\title{
Exploration on the Training Mode of Applied Pharmaceutical Professionals Oriented by Social Needs
}

Ying Zhang, Shijie Wang, Liangtong Li, Lei Diao, Wei Zhang, Junxia Liu, Yujie Li

Jilin Agricultural Science and Technology University, Jilin 132101, Jilin, China.

Fund Project: The Subject of Higher Education Scientific Research in Jilin Province "Innovation and practice of the training mode of pharmaceutical professionals oriented by social needs"(JGJX2018D197)

Abstract: According to the requirements of the Ministry of Education's transformation, development and classified management, the pharmacy major of Jilin Agricultural Science and Technology University is based on social demand investigations, with the main goal of vocational ability training, take knowledge system and technical ability training as the core, social competence training runs through the whole process. And the university closely integrates with market demands, and comprehensively improve the quality of pharmacy professional training through clarifying the training objectives of professional talents, integrating the curriculum system, improving teaching methods and perfecting the assessment and evaluation system of teaching links.

Keywords: Social Demands; Pharmacy Majors; Talent Training Model

Under the background of the health industry in the new era, combined with the current higher education transformation, development and classified management requirements, the pharmacy-related majors' transformation and development of our university conform to the needs of the industry. According to the needs of pharmacy professional positions, the universityenterprise integration model has explored the cultivation of students' future life competence, such as humanities quality education, professional quality education, physical and mental quality education model. The university focus on improving the ability of pharmacy graduates to manage the quality of life in the future and workplace so as to meet the social demand for professionals in the pharmaceutical industry.

\section{University-enterprise alliance, formulating talent training goals based on job requirements}

In order to shorten the employment gap, we established a University-Enterprise Cooperation Talent Training Council, and held regular meetings to adjust the training goals of pharmacy professionals according to social needs. Furthermore, the university enables students to work in medical research institutes, medical production and distribution companies, medical supervision and management fields.

\section{Professional integration, integrating the curriculum system through talent training goals}

The university is implementing the credit system gradually, breaking discipline barriers, finding a balance between academic and skill training goals, optimizing the curriculum structure, and enhancing independent learning, focuses on the harmonious unity of knowledge, ability and quality.

2.1 Consolidate humanistic quality education and enhance the ability to manage the quality of life in the future

According to the current situation of higher education, we has established a humanistic quality education system including

Copyright $(2020$ Ying Zhang et al.

doi: 10.18686/ahe.v4i10.2946

This is an open-access article distributed under the terms of the Creative Commons Attribution Non-Commercial License (http://creativecommons. org/licenses/by-nc/4.0/), which permits unrestricted non-commercial use, distribution, and reproduction in any medium, provided the original work is properly cited. 
ideological and moral education, medical history and culture education, career planning, innovation and entrepreneurship education, interpersonal communication and cooperation ability education, nation and country feelings education, the sense of global community of common destiny education and mental health education. These are the core qualities that are indispensable in the employment competition of college students, which directly affect the ability to manage the quality of life in the future ${ }^{[1]}$.

\subsection{Strengthen professional quality education and improve the ability to control future positions}

We starts from various aspects of students' morality, intelligence, physical education, and art, and then organically combines professional core skills with humanistic quality education ${ }^{[2]}$. Firstly, we innovates the education model, focuses on building a professional core curriculum system, integrates theory and practice content, and builds a comprehensive experimental course group based on Clinical Traditional Chinese Medicine and Prescriptions, Pharmacology, Traditional Chinese Medicine Chemistry, Traditional Chinese Medicine Processing, Traditional Chinese Medicine Identification Experiments, etc. We pays attention to connotation development and quality construction. Secondly, coordinate the concept of green development. Education runs through the balance between the development of the pharmaceutical industry and environmental protection, which is in line with national policies. Thirdly, cultivate the awareness of openness and shared development. Through the training of great health thinking, we should pay attention to cultivating the overall concept of students. From the perspective of the overall development trend of the global pharmaceutical industry, Chinese and Western medicine should be integrated, upright and innovative, and mutually beneficial. Improve students' professional core skills and enhance their ability to control future positions.

\subsection{Attach importance to physical and mental quality education and improve the ability to regulate and control the quality of future life}

Physical and mental quality is the foundation of the professional development of college students, and only physical and mental health can follow-up to realize self-worth ${ }^{[3]}$. Firstly, cultivate students' lifelong sports ability through clubs. Cultivate self-awareness, correct motivation for sports activities, and master the skills to maintain self-health. The second is to cultivate students' self-reflection ability through the second course and other activities, improve their ability to analyze and judge problems, seek solutions, not follow blindly, and have strong willpower and action, so as to achieve the perfection of selfpersonality. Thirdly, use courses and activities as the carrier to cultivate students' interpersonal relationship coordination ability, through mutual communication and cooperation to achieve effective communication, improve personal emotional control ability, and efficiently complete job tasks ${ }^{[4]}$.

\section{Full education, faculty is an important guarantee to achieve the goal of talent training}

Higher education is facing a new situation in the new era, and under the guidance of social needs, higher requirements are put forward for the important role of pharmacy teachers in talent training.

\subsection{Insist on taking morality education as the fundamental task}

We adheres to the policy of morality education, regards morality education as the fundamental purpose of university education, and extends it to every aspect of teaching and educating students ${ }^{[5]}$. Insist on the unity of teaching and educating students, persist in the unity of preaching and deeds, inquiring and paying attention to society, academic freedom and academic norms, and achieve full-staff education, full-process education, and all-round education.

\subsection{Adhere to the combination of internal training and external introduction}

Pharmacy majors has good enrollment, however, the number of professional teachers is insufficient, which is a problem that exists in various universities in different degrees. Our university adopts the method of "internal training and external introduction" to strengthen the construction of the teaching staff. One of the methods is the internal training, sending key teachers to domestic and foreign universities or pharmaceutical companies to carry out better learning and training, or young teachers to the college laboratory and base to exercise, improve professional skills. Support and encourage young key teachers to study for doctoral degrees, and give full play to the stabilizing role of teachers in the university. The second is to directly introduce high-level teachers from other pharmacy colleges and universities, guide the development direction and disciplines of the college, and have discussions with teachers and students to enhance the overall development strength of the college. The third is to introduce or employ teachers with rich experience in the pharmaceutical industry or hospitals. Such as the Basic 
Chinese Medicine course, and employ doctors with more than 20 years of medical experience to undertake classroom teaching tasks, and the teaching effect is obvious. Then we has a multi-channel, omnidirectional and three-dimensional pharmacy undergraduate comprehensive practical ability training model.

\section{Taking job abilities as the goal, vigorously promote the curriculum revolution}

The course is the last mile to achieve the goal of talent training. Taking students as the center, improving curriculum teaching and enhancing teachers' teaching ability and level is an important guarantee for the implementation of talent training. We organizes more than 30 key teachers to participate in various teaching trainings every year, so that teachers can change their concepts, focus on the cultivation of perceptual literacy and adaptability, change the phenomenon of lack of students in the teaching process, study together with students, and strengthen academic analysis. Grasp the learning situation in time and strengthen the communication between teachers and students.

\subsection{Constructing a great ideological and political pattern with curriculum as the carrier}

We attaches importance to the combination of political curriculum and ideological and political studies, and carries out implicit ideological and political education. Both the Medicinal Chemistry and Biochemistry courses are implicitly integrated with ideological and political elements from multiple angles. The pharmacognosy training session focuses on the elements of Chinese medicine, carry out Chinese medicine painting competitions, promote learning with competitions, and build a great ideological and political education pattern. The essence of education is to cultivate the mind.

\subsection{Promote teaching reform by means of educational resources}

We increase investment in educational resources, update teaching equipment and facilities, and enrich teaching reform models through spatial changes. We makes full use of teaching information resources such as the Internet, multimedia, mobile terminals, various assessment software, and virtual simulation experiment platforms to promote the teaching and assessment methods of "student-centered" and "self-learning".

\subsection{Improving the management and feedback system of teaching links based on the double circulation model}

Effectively use the university's teaching quality monitoring system, especially the teaching quality evaluation system and teaching quality feedback system, and collect feedback from industry, employers and students in a timely manner. Adjust the teaching goals, promote the scientific and standardized teaching quality management of the university, and establish a scientific and reasonable teaching quality assurance system that combines daily teaching management and teaching evaluation. Create a good teaching environment, achieve the best teaching effect, promote the continuous deepening of the reform and construction of the university, and continuously improve and enhance the quality of talent training.

The exploration of the training model of applied pharmacy professionals based on social needs is a long-term process. Continue to accumulate experience in the exploration process, make adjustments timely according to social needs, and improve continuously. Effectively support the society's demand for pharmaceutical professionals with solid basic knowledge and skills, broad knowledge, strong adaptability, and innovative consciousness in the pharmaceutical industry.

\section{References}

1. Li LH. The important position of humanistic liberal education in the promotion of social competitiveness of colleges and universities and teaching countermeasures. Survey of Education 2019; 8(27): 54-55+116.

2. Zhang FY. A probe into the ways of bringing professional core competence into quality-oriented education. Think tank era, 2019; (31): 290-291.

3. LI L. Research on the cultivation of college students comprehensive quality under the background of transformation. Western China Quality Education 2019; 5(12): 45-46.

4. Zhang LH. Construction of evaluation index system of medical students physical and mental quality oriented by "Social Adaptation". Journal of Qiqihar Medical University 2017; 38(24): 2935-2936.

5. Tao H. The realistic examination and realization path of "three comprehensive education" in higher college ideological and political education. Journal of HUBEI Open Vocational College 2019; 32(23): 75-76+79. 